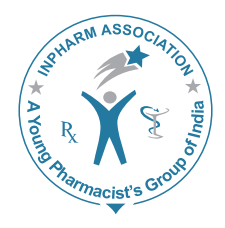

\title{
Extractive Spectrophotometric Method for the Determination of Tropicamide
}

\author{
Shoaibi ZA, Gouda AA ${ }^{1}$ \\ Department of Organic Chemistry, Faculty of Pharmacy, Sana'a University, Sana'a, (YEMEN), \\ ${ }^{1}$ Department of Chemistry, Faculty of Science, Zagazig University, Zagazig, Egypt, Makkah Community \\ College, Department of Medical Science, Umm Al-Qura University, Makkah, Saudi Arabia \\ Address for correspondence: Dr. Ayman Abou El-Fetouh Gouda; E-mail: aymanchimca@yahoo.com
}

\begin{abstract}
Two simple, rapid, and extractive spectrophotometric methods were developed for the determination of tropicamide (TPC). These methods are based on the formation of ionpair complexes between the basic nitrogen of the drug with bromocresol purple (BCP) and methyl orange (MO) in acidic buffer solution. The formed complexes were extracted with chloroform and measured at 408 and $427 \mathrm{~nm}$ using BCP and MO, respectively. Beer's law was obeyed in the range $1.0-16 \mathrm{\mu g} \mathrm{ml}^{-1}$ with correlation coefficient $(n=6) \geq 0.9991$. The molar absorpitivity, Sandell sensitivity, detection, and quantification limits were also calculated. The composition of the ion pairs was found 1:1 by Job's method. The proposed methods have been applied successfully for the analysis of TPC in pure and in its eye drops.
\end{abstract}

Key words: Bromocresol purple, ion pair complex, methyl orange, pharmaceutical formulations, spectrophotometry, tropicamide

\section{INTRODUCTION}

Tropicamide (TPC), [Scheme 1] (R,S)-N-ethyl-3hydroxy-2-phenyl- $N$-(pyrid-4-ylmethyl) propionamide, is a tropic acid derivative endowed with short duration of antimuscarinic activity and available in 0.5 and $1 \%$ ophthalmic solutions. Its maximum effect is achieved in about 20-25 min and lasts about $20 \mathrm{~min}$, with complete recovery being noted in about $6 \mathrm{~h}$. Its action is more rapid

\begin{tabular}{|l|l|}
\hline \multicolumn{2}{|c|}{ Access this article online } \\
\hline Quick Response Code: & \\
\cline { 1 - 1 } & Website: \\
& www.jyoungpharm.in \\
& \\
\hline
\end{tabular}

in onset and wears off more rapidly than most other mydriatics. Its uses are generally much the same as those described for other mydriatics. ${ }^{[1,2]}$ Since tropicamide use is increasing, it is very much essential to develop simple and suitable analytical method for its quantification in bulks and formulations. Such method should provide proper

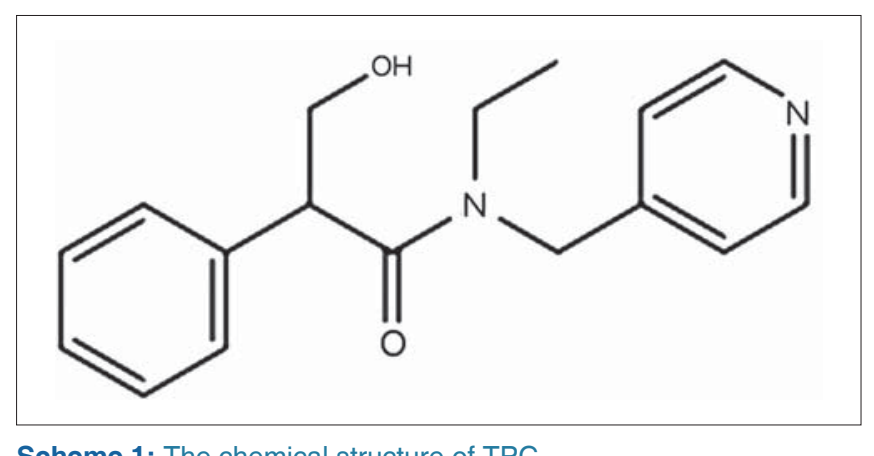

Scheme 1: The chemical structure of TPC

Journal of Young Pharmacists / Vol 4 / No 1 
sensitivity and selectivity and could be easily adapted for routine quality control analysis, preformulation or similar studies.

There is little information in the literature for quantification of tropicamide in pharmaceutical raw materials and dosage forms. ${ }^{[3,4]}$ The reported analytical methods for determination of TPC are TLC, ${ }^{\left[{ }^{[1]}\right.}$ spectrophotometry, ${ }^{[0-8]}$ and HPLC. ${ }^{[9,10]}$ The United States Pharmacopoeia (USP) and British Pharmacopoeia $(\mathrm{BP})^{[11,12]}$ have described a nonaqueous titration for determination of tropicamide in raw material and an extractive spectrophotometric method for its pharmaceutical preparations. These methods are time consuming and costly for routine analysis. Therefore, having a simple, fast, and accurate method for determination of TPC in raw material and pharmaceutical dosage forms, which can be used in quality control laboratories is a necessity.

Extractive spectrophotometric procedures are popular for their sensitivity in the assay of drugs. The wellestablished spectrophotometric method employed ion-pair extraction. In this case, an ion-pair is formed between basic pharmaceutical compounds and an anionic dye such as bromocresol purple (BCP) and methyl orange (MO). At a specific $\mathrm{pH}$, the ion-pair is extracted into an organic solvent, which is immiscible with water, and the concentration of the resulting ion pair in the organic phase is determined spectrophotometrically. ${ }^{[13-19]}$

The present study aims to develop accurate, reproducible, less time consuming, and adequately sensitive validated extractive spectrophotometric methods based on the formation of ion-pair complexes between TPC with bromocresol purple (BCP) and methyl orange (MO). The proposed methods were applied to the determination of TPC in tablets dosage form. No interference was observed in the assay of TPC from common excipients in levels found in dosage form. These methods are validated by the statistical data and can be adopted by the pharmaceutical laboratories for industrial quality control.

\section{MATERIALS AND METHODS}

\section{Apparatus}

All absorption spectra were made using Optima UV-VIS spectrometer (SP-3000 plus) (Tokyo, Japan), equipped with $10 \mathrm{~mm}$ matched quartz cells. Hanna $\mathrm{pH}$-meter instrument ( $\mathrm{pH}$ 211) (Romania) was used for checking the $\mathrm{pH}$ of Buffer solutions.
Materials and reagents

All chemicals and reagents were of analytical grade and water was always bidistilled water.

\section{Materials}

Tropicamide (TPC) was kindly supplied by Alexandria pharmaceutical Industries Company (Alex), Alexandria, Egypt.

\section{Pharmaceutical formulations}

Mydrapid drops (Alex, Alexandria, Egypt), labeled to contain $(0.5 \%$ and $1.0 \%)$ TPC.

\section{Standard solution}

A stock standard solution $\left(100 \mu \mathrm{g} \mathrm{ml}^{-1}\right)$ and $\left(1.0 \times 10^{-3} \mathrm{M}\right)$ of TPC were prepared by dissolving appropriate weight 0.01 and $0.0284 \mathrm{~g}$, respectively of pure TPC in $10 \mathrm{ml}$ of methanol and further diluted with double distilled water up to the mark in $100 \mathrm{ml}$ volumetric flask. Working standard solutions were prepared by suitable dilution of stock standard solution with bidistilled water. The solution remained stable for 1 month when kept refrigerated.

\section{Reagents}

Bromocresol purple (BCP) and methyl orange $(\mathrm{MO})(\mathrm{BDH}$ Chemicals LTD, Poole, England) and used without further purification.

A stock solution $\left(1.0 \times 10^{-3} \mathrm{M}\right)$ was prepared by dissolving the appropriate weight of bromocresol purple (BCP) and methyl orange (MO) in $10 \mathrm{ml}$ methanol and diluted to $100 \mathrm{ml}$ with bidistilled water.

These solutions are stable for at least 1 week if kept in the refrigerator.

Series of buffer solutions of $\mathrm{KCl}-\mathrm{HCl}(\mathrm{pH}$ 1.5-4.2), $\mathrm{NaOAc}-\mathrm{HCl}$ (pH 1.99-4.92), $\mathrm{NaOAc}-\mathrm{AcOH}$ (pH 2.8-6.0) and potassium hydrogen phthalate- $\mathrm{HCl}(\mathrm{pH} 2.0-6.0)$ were prepared by following the standard methods. ${ }^{[20]}$ Freshly prepared solutions were always employed.

\section{Construction of calibration curves}

Aliquots of TPC ranging from 0.1 to $1.6 \mathrm{ml}$ of standard solution $\left(100 \mu \mathrm{g} \mathrm{l}^{-1}\right)$ were transferred into a series of $100 \mathrm{ml}$ separating funnels. To each separating funnel $2.0 \mathrm{ml}$ of $\mathrm{BCP}$ or MO $\left(1.0 \times 10^{-3} \mathrm{M}\right)$ reagent solutions and $3.0 \mathrm{ml}$ potassium hydrogen phthalate- $\mathrm{HCl}$ buffer of $\mathrm{pH} 3.0$, were added and the volume of the aqueous layer was adjusted to 
$10 \mathrm{ml}$ with distilled water. The mixture was extracted twice with $2.0 \times 5.0 \mathrm{ml}$ chloroform by shaking for $2.0 \mathrm{~min}$, then allowed to stand for clear separation of the two phases and the chloroform layer was passed through anhydrous sodium sulphate. The chloroform extracts were collected and diluted to $10 \mathrm{ml}$ with chloroform. The absorbance of the yellow colored complexes were measured at 408 and $427 \mathrm{~nm}$ using $\mathrm{BCP}$ and $\mathrm{MO}$, respectively against the reagent blank similarly prepared. All measurements were made at room temperature $\left(25 \pm 2^{\circ} \mathrm{C}\right)$. The procedures were repeated for other analyte aliquots and calibration plots were drawn to calculate the amount of drug in unknown analyte samples.

\section{Procedure for determination of TPC in dosage form}

The content of five eye drop container were mixed in a beaker and the average volume of one eye drop container was determined and transferred into $100 \mathrm{ml}$ volumetric flask and completed to $100 \mathrm{ml}$ with bidistilled water and further dilution with bidistilled water was carried out to obtain test solution of $100 \mu \mathrm{g} \mathrm{m} l^{-1}$ of TPC. The general procedures described above were used for the determination of TPC concentration.

\section{RESULTS}

\section{Absorption spectra}

The nitrogenous drugs are present in positively charged protonated forms and acidic dyes present mainly in anionic form at $\mathrm{pH} \geq 2.5$. So when treated with an acid dye at $\mathrm{pH}$ range (2.0-6.0) of potassium hydrogen phthalate- $\mathrm{HCl}$ buffer, a yellow ion-pair complex which is extracted with chloroform is formed. The absorption spectra of the ionpair complexes, which were formed between TPC and each of $\mathrm{BCP}$ and $\mathrm{MO}$ were measured in the range $350-550 \mathrm{~nm}$ against the blank solution. The ion-pair complexes show maximum absorbance at 408 and $427 \mathrm{~nm}$ using $\mathrm{BCP}$ and $\mathrm{MO}$ methods, respectively. The optimum reaction conditions for determination of the ion-pair complexes were established. Then linearity, accuracy, precision, sensitivity, and stability of proposed methods were described and these developed methods applied to pharmaceutical preparations and obtained results evaluated statistically.

\section{Optimum reaction conditions for complex formation}

The optimization of the methods was carefully studied to achieve complete reaction formation, highest sensitivity and maximum absorbance. Reaction conditions of the ion-pair complex were found by studying with preliminary experiments such as $\mathrm{pH}$ of buffer, type of organic solvent, volumes of the dye, and shaking time for the extraction of ion-pair complexes.

\section{Selecting of the extracting solvents}

The effect of several extracting organic solvents on the ion-pair complex was examined. Chloroform, carbon tetrachloride, ethyl acetate, diethylether, toluene, 1,2-dichloroethane and dichloromethane were tried for effective extraction of the colored ion pair complex from aqueous phase. Chloroform was found to be the most suitable solvent for extraction of colored complex through double extraction with $5.0 \mathrm{ml}$ each time, because of its higher efficiency on color intensity, selective extraction of the ion-pair complex from the aqueous phase, obtained highest absorbance with chloroform and considerably lower extraction ability for the reagent blank and the shortest time to reach the equilibrium between both chloroform and aqueous phases.

\section{Effect of time and temperature}

The optimum reaction time was investigated from 0.5 to $4.0 \mathrm{~min}$ by following the color development at ambient temperature $\left(25 \pm 2^{\circ} \mathrm{C}\right)$. Complete color intensity was attained after 2.0 min of mixing for all complexes. Raising the temperature up to $30^{\circ} \mathrm{C}$ had no effect on the absorbance of the formed complexes, whereas above $30^{\circ} \mathrm{C}$, the absorbance started to decay. The absorbance remained stable for at least $24 \mathrm{~h}$.

\section{Effects of $\mathrm{pH}$ on the ion-pair formation}

The effect of $\mathrm{pH}$ was studied by extracting the colored complexes in the presence of various buffers such as $\mathrm{KCl}-\mathrm{HCl}$ (pH 1.5-4.2), NaOAc-HCl (pH 1.99-4.92), $\mathrm{NaOAc}-\mathrm{AcOH}(\mathrm{pH} 2.8-6.0)$, and potassium hydrogen phthalate- $\mathrm{HCl}(\mathrm{pH} 2.0-6.0)$. It was noticed that the maximum color intensity and highest absorbance value were observed in potassium hydrogen phthalate- $\mathrm{HCl}$ buffer of $\mathrm{pH} 3.0$ is the optimum $\mathrm{pH}$ values of buffer using $\mathrm{BCP}$ and MO, respectively. In addition to the stability of the color without affecting the absorbance at the optimum $\mathrm{pH}$ values [Figure 1]. Further, $3.0 \mathrm{ml}$ of phthalate buffer gave maximum absorbances and reproducible results.

\section{Effects of reagents concentration}

The effect of the reagents was studied by measuring the absorbance of solutions containing a fixed concentration of TPC $\left(10 \mu \mathrm{g} \mathrm{ml}^{-1}\right)$ and varied amounts of the respective reagent. Maximum color intensity of the complex was achieved with $2.0 \mathrm{ml}$ of $\mathrm{BCP}$ or $\mathrm{MO}\left(1.0 \times 10^{-3} \mathrm{M}\right)$ reagent 
solutions, respectively. Although a larger volume of the reagent had no pronounced effect on the absorbances of the formed ion-pair complex [Figure 2].

\section{Effect of sequence of mixing}

The most favorable sequence was (drug-reagent-buffersolvent) for the highest color intensity and the shortest time for developing maximum absorbance, while the other sequences require longer time and produce lower absorbance values.

\section{Stoichiometric relationship}

Job's method of continuous variation and mole-ratio method $^{[21,22]}$ of equimolar solutions was employed: A $1.0 \times 10^{-4} \mathrm{M}$ standard solution of drug base and $1.0 \times 10^{-4} \mathrm{M}$ solution of $\mathrm{BCP}$ and $\mathrm{MO}$, respectively, were used. A series of solutions was prepared in which the total volume of drug and reagent was kept at $10 \mathrm{ml}$ for BCP and $\mathrm{MO}$, respectively. The absorbance was measured at the optimum wavelength. The molar ratio of the reagents (drug: dye) in the ion-pair complexes was determined by the continuous variations method (Job's method) [Figure 3].

The results indicate that 1:1 (drug:dye) ion-pairs are formed through the electrostatic attraction between positive protonated $\mathrm{TPC}^{+}$and negative $\mathrm{BCP}^{-}$and $\mathrm{MO}^{-}$. The extraction equilibrium can be represented as follows:

$\mathrm{TPC}^{+}+\mathrm{D}^{-}(\mathrm{aq}) \leftrightarrow \mathrm{TPC}^{+} \mathrm{D}^{-}(\mathrm{aq}) \leftrightarrow \mathrm{TPC}^{+} \mathrm{D}^{-}(\mathrm{org})$

where $\mathrm{TDF}^{+}$and $\mathrm{D}^{-}$represent the protonated TDF and the anion of the dye, respectively, and the subscript (aq) and (org) refer to the aqueous and organic phases, respectively. The suggested mechanism of TPC-BCP ion-pair complex formation is presented in Scheme 2.

The stability of the ion-pair complexes was evaluated. The formation of the ion-pairs were rapid and the yellow color extracts were stable $24 \mathrm{~h}$ for drug-dye without any change in color intensity and the maximum absorbance at room temperature.

\section{DISCUSSION}

\section{Method validation}

\section{Linearity}

At described experimental conditions for TPC determination, standard calibration curves for TPC with BCP and MO calibrations were constructed by plotting absorbance vs.

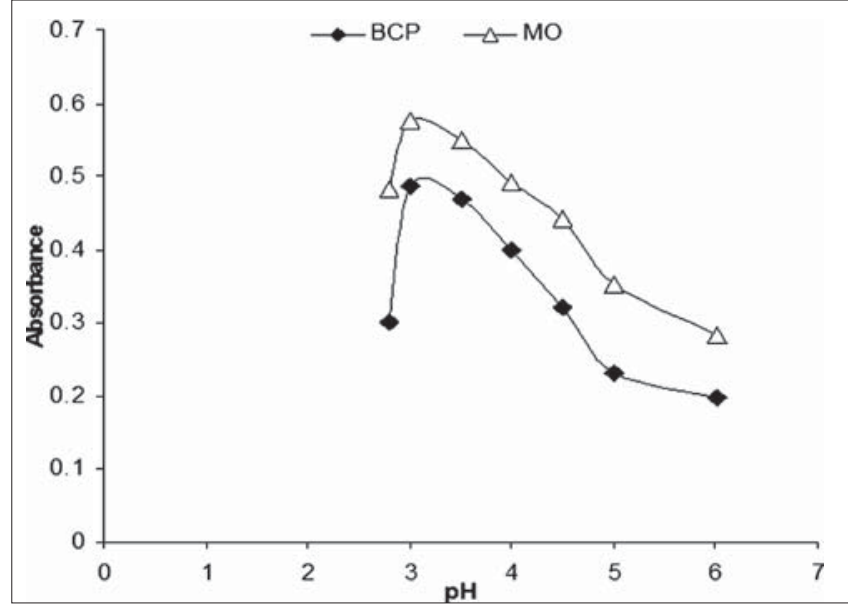

Figure 1: Effect of $\mathrm{pH}$ of potassium hydrogen phthalate- $\mathrm{HCl}$ buffer solution on the ion-pair complexes of $\left(10 \mu \mathrm{g} \mathrm{ml}^{-1}\right)$ TPC with $\left(1.0 \times 10^{-3} \mathrm{M}\right)$ dyes

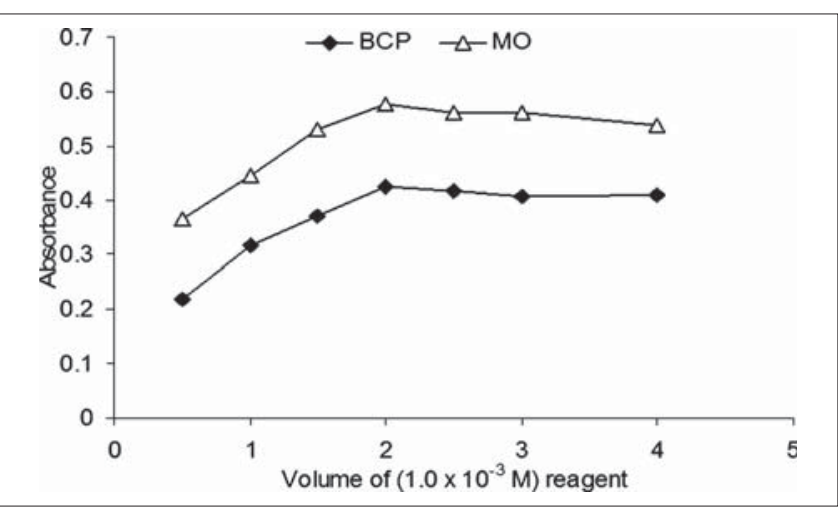

Figure 2: Effect of volume of $\left(1.0 \times 10^{-3} \mathrm{M}\right)$ of $\mathrm{BCP}$ and $\mathrm{MO}$ reagent concentration on the reaction of $\left(10 \mu \mathrm{g} \mathrm{ml}^{-1}\right)$ TPC with dye

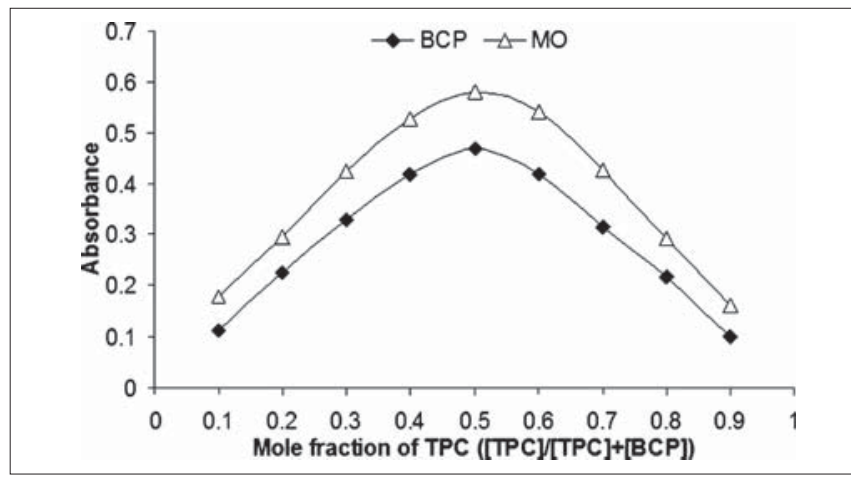

Figure 3: Job's method of continuous variation graph for the reaction of TPC with dyes BCP and MO, [drug] $=[$ dye $]=1 \times 10^{-4} \mathrm{M}$

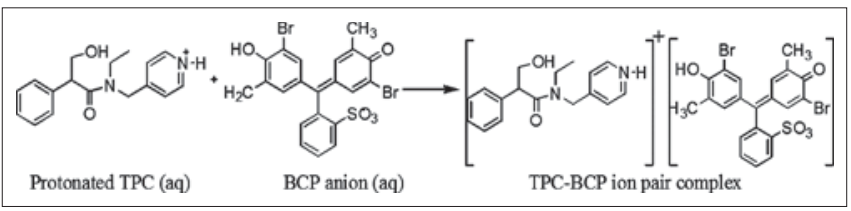

Scheme 2: Structure of analyte and formed ion-paired complex, positively charged nitrogen of TPC and negatively charged sulfonate of BCP forms an ion-pair complex soluble in organic solvents 
concentration. The statistical parameters were given in the regression equation calculated from the calibration graphs. The proposed methods were validated as per the ICH guidelines. ${ }^{[23-25]}$ The linearity of calibration graphs was proved by the high values of the correlation coefficient $(r)$ and the small values of the $y$-intercepts of the regression equations. The apparent molar absorptivities $(\varepsilon)$ was calculated and found to be $1.641 \times 10^{4}$ and $1.072 \times 10^{4} \mathrm{lmol}^{-1} \mathrm{Cm}^{-1}$ for BCP and MO ion-pair complexes, respectively, indicating high sensitivity of $\mathrm{BCP}$ than $\mathrm{MO}$ reagent. Relative standard deviation of response factors for each proposed spectrophotometric method were also calculated and recorded in Table 1.

\section{Sensitivity}

The detection limit (LOD) for the proposed methods was calculated using the following equation: ${ }^{[26]}$

$\mathrm{LOD}=3 s / k$,

where $s$ is the standard deviation of replicate determination values under the same conditions as for the sample analysis in the absence of the analyte, and $k$ is the sensitivity, namely the slope of the calibration graph. In accordance with the formula, the detection limits were found to be 0.091 and $0.237 \mu \mathrm{g} \mathrm{ml} \mathrm{m}^{-1}$ for BCP and $\mathrm{MO}$ methods, respectively.

The limits of quantization, LOQ, is defined $\mathrm{as}^{[26]}$

$\mathrm{LOQ}=10 s / k$.

According to this equation, the limit of quantization was found to be 0.303 and $0.791 \mu \mathrm{g} \mathrm{ml} \mathrm{m}^{-1}$ for BCP and MO methods, respectively.

\section{Accuracy and precision}

Percentage relative standard deviation (RSD\%) as precision and percentage relative error $(\mathrm{Er} \%)$ as accuracy of the suggested method were calculated. Precision was carried out by six determinations at four different concentrations in these spectrophotometric methods. The percentage relative error calculated using the following equation:

$\operatorname{Er} \%=[($ founded - added $) /$ added $] \times 100$.

The interday and intraday precision and accuracy results are shown in Table 2. These results of accuracy and precision show that the proposed methods have good repeatability and reproducibility.
Table 1: Statistical analysis of calibration graphs and analytical data in the determination of TPC using the proposed methods $(n=6)$

\begin{tabular}{|c|c|c|}
\hline \multirow[t]{2}{*}{ Parameters } & \multicolumn{2}{|c|}{ The proposed methods } \\
\hline & BCP & MO \\
\hline Wavelengths $\lambda_{\text {max }}(\mathrm{nm})$ & 408 & 427 \\
\hline Beer's law limits $\left(\mu \mathrm{g} \mathrm{ml}^{-1}\right)$ & $1.0-10$ & $2.0-16$ \\
\hline Ringbom optimum range $\left(\mu \mathrm{g} \mathrm{ml}^{-1}\right)$ & $3.0-8.5$ & $4.0-14$ \\
\hline Molar absorptivity $\varepsilon\left(1 / \mathrm{mol}^{-1} \mathrm{~cm}^{-1}\right) \times 10^{4}$ & 1.641 & 1.072 \\
\hline Sandell, s sensitivity $\left(\mathrm{ng} \mathrm{cm}^{-2}\right.$ ) & 17.33 & 26.53 \\
\hline \multicolumn{3}{|l|}{ Linear regression equation ${ }^{\mathrm{a}}$} \\
\hline Intercept $(a)$ & 0.0322 & 0.0553 \\
\hline Slope $(b)$ & 0.0462 & 0.0471 \\
\hline Correlation coefficient $(r)$ & 0.9997 & 0.9991 \\
\hline Limit of detection LOD $\left(\mu \mathrm{g} \mathrm{ml}^{-1}\right)$ & 0.091 & 0.160 \\
\hline limit of quantification LOQ $\left(\mu \mathrm{g} \mathrm{ml}^{-1}\right)$ & 0.303 & 0.532 \\
\hline Recovery\% & 100.03 & 99.70 \\
\hline RSD $\%$ & 0.837 & 0.749 \\
\hline $\mathrm{RE} \%$ & 0.879 & 0.786 \\
\hline$t$-test $\mathrm{t}^{\mathrm{b}}$ & 0.906 & 0.387 \\
\hline$F$-test $^{\mathrm{b}}$ & 1.727 & 2.157 \\
\hline
\end{tabular}

${ }^{a} A=a+b C$, where $C$ is the concentration in $\mu \mathrm{g} \mathrm{ml}^{-1}, y$ is the absorbance units. ${ }^{b}$ The theoretical values of $t$ and $F$ at $P=0.05$ are 2.571 and 6.39, respectively

Table 2: I ntraday and I nterday precision and accuracy data for TPC obtained by the proposed methods

\begin{tabular}{lccccc}
\hline Method & $\begin{array}{c}\text { Added } \\
\text { concentration } \\
\left(\mu \mathrm{g} \mathrm{ml} \mathbf{l}^{-1}\right)\end{array}$ & $\begin{array}{c}\text { Recovery } \\
(\%)\end{array}$ & $\begin{array}{c}\text { Precision } \\
\text { RSD }(\%)^{\mathrm{a}}\end{array}$ & $\begin{array}{c}\text { Accuracy } \\
\text { Er } \%\end{array}$ & $\begin{array}{c}\text { Confidence } \\
\text { limit }^{\mathrm{b}}\end{array}$ \\
\hline Intraday & & & & & \\
BCP & 2.0 & 99.80 & 0.65 & -0.20 & $1.996 \pm 0.013$ \\
& 4.0 & 100.03 & 0.84 & 0.03 & $4.001 \pm 0.0336$ \\
& 6.0 & 99.40 & 0.87 & -0.60 & $5.964 \pm 0.0519$ \\
& 8.0 & 99.79 & 0.92 & -0.21 & $7.983 \pm 0.0734$ \\
MO & 4.0 & 99.65 & 1.04 & -0.35 & $3.986 \pm 0.0414$ \\
& 8.0 & 100.20 & 0.69 & 0.20 & $8.016 \pm 0.0553$ \\
& 12 & 99.85 & 0.45 & -0.15 & $11.982 \pm 0.0539$ \\
Inter-day & 16 & 100.20 & 0.34 & 0.20 & $16.032 \pm 0.0545$ \\
BCP & 2.0 & 100.10 & 0.55 & 0.10 & $2.002 \pm 0.011$ \\
& 4.0 & 99.60 & 0.80 & -0.40 & $3.984 \pm 0.0319$ \\
& 6.0 & 99.55 & 0.61 & -0.45 & $5.973 \pm 0.0364$ \\
& 8.0 & 99.85 & 0.72 & -0.15 & $7.988 \pm 0.0575$ \\
MO & 4.0 & 100.05 & 1.03 & 0.05 & $4.002 \pm 0.0488$ \\
& 8.0 & 99.95 & 0.90 & -0.05 & $7.996 \pm 0.0720$ \\
& 12 & 99.80 & 0.64 & -0.20 & $11.976 \pm 0.0766$ \\
& 16 & 99.65 & 0.50 & -0.35 & $15.944 \pm 0.0797$
\end{tabular}

${ }^{\mathrm{a}}$ Mean of five determination, RSD\%: Percentage relative standard deviation; $\mathrm{Er} \%$ : Percentage relative error. ${ }^{b}$ Confidence limit at 95\% confidence level and five degrees of freedom $(t=2.776)$

\section{Effects of interference}

To assess the usefulness of the method, the effect of diluents, excipients and additives which often accompany TPC in its dosage forms (lactose, dextrose, ethanol, starch, propylene glycol, hydroxypropyl methyl cellulose, cellulose) was studied. The results indicated that there is no interference from the degradation, indicating a high 
selectivity for determining the studied TPC in its dosage forms (eye drops).

\section{Analysis of pharmaceutical preparations}

The suggested methods were applied successfully to the determination of TPC in commercial eye drops. Six replicate determinations were made. Table 3 shows that satisfactory recovery data were obtained and the assay results were in a good agreement with the label claims.

Moreover, to check the validity of the proposed methods, dosage forms were tested for possible interference with standard addition method. There was no significant difference between slopes of calibration curves and standard addition methods at two methods. Therefore it is concluded that the excipients in dosage forms of TPC were not found any interference in the analysis of TPC. At 95\% confidence level the calculated $F$-value did not exceed the theoretical $F$-value indicating no significant difference between the two proposed methods and the offical method (non aqueous titration method described in $\mathrm{BP})^{[12]}$ [Table 4].

\section{CONCLUSION}

Spectrophotometric analysis is of major interest in analytical pharmacy since it offers distinct possibility in the assay of a particular component in dosage formulations. In the present study, the maximum color development of TPC with BCP or MO ion-pair complex was instantaneous. No heating or standing was needed. These methods do not involve procedural steps, do not take more operator time and expertise such as HPLC and other methods. In terms of simplicity, rapidity, sensitivity, expense, and free from interference by common additives and excipients, the methods could be considered superior in comparison with the previously reported methods, especially with those based on chromatography or other reported spectrophotometric methods. The reagents utilized in the proposed methods are cheaper, readily available and the procedures do not involve any critical reaction conditions or tedious sample preparation. The method is unaffected by slight variations in experimental conditions such as time, reagent concentration or temperature. The proposed methods gave results with good accuracy to permit determination of low concentrations. The wide applicability of the described procedure for routine quality control is well established by the assay of TPC in pure form, as well as in tablets dosage forms.
Table 3: Determination of TPC in pharmaceutical dosage form (eye drops) applying the standard addition technique

\begin{tabular}{lcccc}
\hline Sample & $\begin{array}{c}\text { Taken } \\
\left(\mu \mathrm{ml}^{-1}\right)\end{array}$ & $\begin{array}{c}\text { Added } \\
\left(\mu \mathrm{m} \mathrm{ml}^{-1}\right)\end{array}$ & \multicolumn{2}{c}{$\begin{array}{c}\text { Proposed methods } \\
\text { recovery }\end{array}$} \\
\cline { 3 - 5 } & & & BCP & MO \\
\hline Mydrapid drops (0.5\%) & 2.0 & 2.0 & $99.95 \pm 0.41$ & $99.70 \pm 0.58$ \\
& & 4.0 & $99.85 \pm 0.62$ & $99.65 \pm 0.67$ \\
& & 6.0 & $100.05 \pm 0.48$ & $99.90 \pm 0.54$ \\
Mydrapid drops (1\%) & 2.0 & 8.0 & $100.15 \pm 0.54$ & $99.40 \pm 0.83$ \\
& & 4.0 & $99.55 \pm 0.49$ & $99.75 \pm 0.60$ \\
& & 6.0 & $99.65 \pm 0.66$ & $99.50 \pm 0.56$ \\
& & 8.0 & $99.90 \pm 0.74$ & $99.60 \pm 0.51$ \\
\hline
\end{tabular}

${ }^{a}$ Average of six determinations

Table 4: Determination of TPC in pharmaceutical dosage form (eye drops)

\begin{tabular}{lccc}
\hline Sample & $\begin{array}{c}\text { Official } \\
\text { method }^{[11]} \\
(n=6)\end{array}$ & \multicolumn{2}{c}{$\begin{array}{c}\text { Proposed methods }(n=6), \\
\text { recovery\% }\end{array}$} \\
\cline { 3 - 4 } & & BCP & MO \\
\hline Mydrapid drops (0.5\%) & $99.40 \pm 0.70$ & $99.94 \pm 0.65$ & $99.75 \pm 0.50$ \\
& & $t^{*}=1,26$ & $t^{*}=0.91$ \\
Mydrapid drops (1.0\%) & $100.10 \pm 0.64$ & $99.80 \pm 0.75$ & $99.68 \pm 0.86$ \\
& & $F^{*}=1.16$ & $F^{*}=1.96$ \\
& & $F^{*}=1.37$ & $F^{*}=1.81$ \\
\hline
\end{tabular}

${ }^{a}$ Average of six determinations. *The theoretical values of $t$ and $F$ at $P=0.05$ are 2.31 and 6.39 , respectively

\section{REFERENCES}

1. Hardman JG, Gilman AG, Limbird LE. The pharmacological pasis of therapeutics, $10^{\text {th }}$ ed. New York: McGraw-Hill; 2001. p. 1673-85.

2. Delgabo JN, Remers WA. Wilson and Gisvold's textbook of organic medicinal and pharmaceutical chemistry. $10^{\text {th }}$ ed. New York: LippincottRaven Publ; 2004. p. 585.

3. Timm U, Göber B, Döhnert H, Pfeifer S. Analysis and the stability of tropicamide. Pharmazie 1977;32:331-5.

4. Blessel KW, Rudy BC, Senkowski BZ. Tropicamide. Anal Profile Drug Subst 1974;3:565-89.

5. Alani SD. The ophthalmic rod: A new ophthalmic drug delivery system I. Graefes Arch Clin Exp Ophthalmol 1990;228:297-301.

6. Pohloudek-Fabini R, Martin E, Gallasch V. Contribution to the stability of tropicamide solutions. Pharmazie 1982;37:184-7.

7. Dubey BK, Upadhyayr R, Tiwari AK, Shukla IC. Assay of some ophthalmic drugs with ammonium metavanadate reagent. J Indian Chem Soc 2004;81:511-4.

8. Amanlou M, Asmardi G, Andalibi PC, Javadi N, Khodadady F, Omarny ZB. Determination of tropicamide in pharmaceutical formulations using high-performance liquid chromatography. J Chromatogr A 2005;1088:136-9.

9. Amanlou M, Asmardi G, Andalibi PC, Javadi N, Khodadady F, Omarny ZB. Determination of tropicamide in pharmaceutical formulations using highperformance liquid chromatography. J Chromatogr A 2005;1088:136-9.

10. Stefanowicz Z, Stefanowicz J, Mulas K. Determination of tropicamide and its major impurity in raw material by the HPLC-DAD analysis and identification of this impurity using the off-line HPLC-FT-IR coupling. J Pharm Biomed Anal 2009;49:214-20.

11. United States Pharmacoepia 29. Rockville: United States Pharmacoepial Convention; 2005. p. 295-2223.

12. British Pharmacopoeia. Ph Eur monograph 1159. London: Her Majesty's, Stationery Office; 2007. 
13. Kepekci SE, Oztunc A. Determination of maprotiline hydrochloride by ion-pair extraction using bromophenol blue and bromocresol purple. Acta Pharm Turc 2005;47:65-71.

14. Sudhir Kumar R, Manjunatha DH, Shaikh SM, Seetharamappa J, Harikrishna K. Sensitive extractive spectrophotometric methods for determination of trazodone hydrochloride in pharmaceutical formulations. Chem Pharm Bull (Tokyo) 2006;54:968-71.

15. Goyal A, Singhvi I. Visible spectrophotometric methods for estimation of ambroxol hydrochloride from tablet formulation. Asian J Chem 2005; 17:2836-8.

16. Ashour S, Al-Khalil R. Simple extractive colorimetric determination of levofloxacin by acid-dye complexation methods in pharmaceutical preparations. Farmaco 2005;60:771-5.

17. Amanlou M, Khosravian P, Souri E, Dadrass OG, Dinarvand R, Alimorad MM, et al. Determination of buprenorphine in raw material and pharmaceutical products using ion-pair formation. Bull Korean Chem Soc 2006;28:183-7.

18. Nour El-Dien FA, Mohamed GG, Mohamed NA. Spectrophotometric determination of trazodone, amineptine and amitriptyline hydrochlorides through ion-pair formation using methyl orange and bromocresol green reagents. Spectrochim Acta A Mol Biomol Spectrosc 2006;65:20-6.

19. Harikrishna K, Nagaralli BS, Seetharamappa J. Extractive spectrophotometric determination of sildenafil citrate (Viagra) in pure and pharmaceutical formulations. J Food Drug Anal 2008;6:11-7.
20. Britton HT. Hydrogen Ions. $4^{\text {th }}$ ed. London: Chapman and Hall; 1952.

21. Job P. Spectrochemical methods of analysis. New York: Wiley Intersience; 1971. p. 346.

22. Inczedy J. Analytical applications of complex equilibria. Chichester: Ellis Horwood; 1976. p. 137.

23. Nash RA, Wachter AH. Pharmaceutical Process Validation. In: Swarbrick J, Carolina N. An international. $3^{\text {rd }}$ ed, Vol. 129, Revised and Expanded. New York: Marcel Dekker Inc; 2003. p. 507-522.

24. International Conference on Harmonization of Technical Requirements for the Registration of pharmaceuticals for human use. Validation of Analytical procedures: Methodology. ICH-Q2B. Geneva, Switzerland: International Federation of Pharmaceutical Manufacturers \& Associations (IFPMA); 1996. (CPMP/ICH/281/95).

25. Green JM. A practical guide to analytical method validation. Anal Chem News Feature 1996;68:305A-9.

26. Miller JC, Miller JN. Significance tests. In Statistics in Analytical Chemistry. $3^{\text {rd }}$ ed, Chapter 3. Chichester: Ellis Horwood; 1993.

How to cite this article: Shoaibi ZA, Gouda AA. Extractive spectrophotometric method for the determination of tropicamide. J Young Pharmacists 2012;4:42-8.

Source of Support: Nil, Conflict of Interest: None declared.

Announcement

\section{Android App}

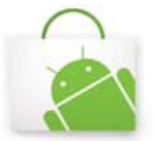

A free application to browse and search the journal's content is now available for Android based mobiles and devices. The application provides "Table of Contents" of the latest issues, which are stored on the device for future offline browsing. Internet connection is required to access the back issues and search facility. The application is compatible with all the versions of Android. The application can be downloaded from https:// market.android.com/details?id=comm.app.medknow. For suggestions and comments do write back to us. 